\title{
Optimalisasi Spasi Ripping Bulldozer terhadap Fragmentasi Batubara Seam B2 di Tambang Banko Barat PT X Desa Tanjung Enim, Kecamatan Lawang Kidul, Kabupaten Muara Enim, Provinsi Sumatera Selatan
}

\author{
Hafizh Nurul Fauzi* \\ Prodi Teknik Pertambagan, Fakultas Teknik, Universitas Islam Bandung, \\ Indonesia. \\ *hafizhnurulfauzi@gmail.com
}

\begin{abstract}
Coal mining at PT X Banko Barat site uses the Strip Mine type Open Mine System using mechanical equipment. To breaking coal from Pit 1 Timur using ripping with the Komatsu D 375 Bulldozer A. As for the digging and loading using Backhoe Komatsu PC 400 and Backhoe Hitachi ZX 470 Lc The problem with the company is the large size of the fragmentation of ripping coal which is greater than $20 \mathrm{~cm}$ which is not in accordance with the specifications of the grizzly dump hopper, so there must be a reduction in the size of the coal back by the backhoe so that production is getting lower. This study aims to optimize the ripping bulldozer space on coal so that it will produce coal fragmentation smaller than the actual ripping and the effect of coal fragmentation on bulldozer and backhoe production. The research included taking data of bulldozer cycle time ripping, backhoe cycle time, bulldozer obstacle time, backhoe obstacle time, coal density and coal fragmentation. From these data we will know the effect of bulldozer ripping spacing on the fragmentation of coal produced and the effect on bulldozer and backhoe production. For the East Pit coal production target, West Banko is 360,000 tons/ month. The actual bulldozer ripping space is $80 \mathrm{~cm}$ with B2 coal fragmentation yield of more than $20 \mathrm{~cm}$ is $11.36 \%$ with $363,476.74$ tons/month ripping bulldozer and backhoe production $363,477.32$ tons/month. For the $60 \mathrm{~cm}$ ripping spacing improvement, the B2 coal fragmentation yield of more than $20 \mathrm{~cm}$ is $3.05 \%$ with a bulldozer ripping production of $347,670.27$ tons/month and backhoe production of $347,670.7$ tons/month. As for the $40 \mathrm{~cm}$ ripping spacing improvement, B2 coal fragmentation which is more than $20 \mathrm{~cm}$ is $1.58 \%$ with a bulldozer ripping production of $288,922.03$ tons / month and backhoe production of 288,922.9 tons/month. Based on the results of the study, coal fragmentation of more than $20 \mathrm{~cm}$ has reached the Company's SOP, which is less than $2 \%$, but the production target has not been reached, so efforts must be made to improve. The improvement effort is by adding a bulldozer and increasing the bulldozer work efficiency. Bulldozer production was obtained at $385,229.37$ tons/month and backhoe production at 385,229.60 tons/month so as to reach the production target.
\end{abstract}

Keywords: ripping space, coal fragmentation, bulldozer ripping, ripping production.

\begin{abstract}
Abstrak. Penambangan batubara pada PT X Site Banko Barat menggunakan Sistem Tambang Terbuka tipe Strip Mine dengan menggunakan peralatan mekanis. Untuk memberaikan batubara pada Pit 1 Timur menggunakan ripping dengan Bulldozer Komatsu D 375 A. Sedangkan untuk penggalian dan pemuatannya menggunakan Backhoe Komatsu PC 400 dan Backhoe Hitachi ZX 470 Lc. Adapun masalah pada perusahaan adalah banyaknya ukuran fragmentasi batubara hasil ripping yang lebih besar dari $20 \mathrm{~cm}$ yang tidak sesuai dengan spesifikasi grizzly dump hopper, sehingga harus ada pengecilan ukuran batubara kembali oleh backhoe sehingga produksinya semakin rendah. Penelitian ini bertujuan untuk mengoptimalkan spasi ripping bulldozer pada batubara sehingga akan menghasilkan fragmentasi batubara yang lebih kecil dibandingkan dengan ripping aktualnya dan pengaruh fragmentasi batubara terhadap produksi bulldozer dan backhoe. Penelitian meliputi pengambilan data cycle time ripping bulldozer, cycle time backhoe, waktu hambatan bulldozer, waktu hambatan backhoe, densitas batubara dan fragmentasi batubara. Dari data tersebut akan diketahui pengaruh dari spasi ripping bulldozer terhadap fragmentasi batubara yang dihasilkan serta pengaruh terhadap produksi bulldozer dan backhoe. Untuk target produksi batubara Pit Timur, Banko Barat adalah 360.000 ton/bulan. Spasi ripping bulldozer aktual adalah sebesar $80 \mathrm{~cm}$ dengan hasil fragmentasi batubara B2 yang lebih dari $20 \mathrm{~cm}$ adalah 11,36\% dengan produksi ripping bulldozer sebesar 363.476,74 ton/bulan dan produksi backhoe sebesar 363.477,32 ton/bulan. Untuk spasi ripping perbaikan $60 \mathrm{~cm}$ dengan hasil fragmentasi batubara B2 yang lebih dari $20 \mathrm{~cm}$ adalah 3,05\% dengan produksi ripping bulldozer sebesar 347.670,27 ton/bulan dan produksi backhoe sebesar 347.670,7 ton/bulan. Sedangkan untuk spasi ripping perbaikan $40 \mathrm{~cm}$ dihasilkan fragmentasi batubara B2 yang lebih dari $20 \mathrm{~cm}$ adalah 1,58\% dengan produksi ripping bulldozer sebesar 288.922,03 ton/bulan dan produksi backhoe sebesar 288.922,9 ton/bulan. Berdasarkan hasil penelitian, fragmentasi batubara yang lebih dari $20 \mathrm{~cm}$ telah mencapai SOP Perusahaan yaitu kurang dari $2 \%$, tetapi target produksinya tidak tercapai, sehingga harus ada upaya perbaikan. Adapun upaya perbaikannya adalah dengan menambahkan satu alat bulldozer dan meningkatkan efisiensi kerja bulldozer. Didapatkan produksi bulldozer sebesar 385.229,37 ton/bulan dan produksi backhoe sebesar $385.229,60$ ton/bulan sehingga telah mencapai target produksi.
\end{abstract}

Kata Kunci : Spasi ripping, fragmentasi batubara, ripping bulldozer, produksi ripping. 


\section{A. Pendahuluan}

\section{Latar Belakang}

Penambangan batubara pada PT X Site Banko Barat menggunakan Sistem Tambang Terbuka tipe Strip Mine dengan menggunakan peralatan mekanis. Untuk memberaikan batubara pada Pit 1 Timur menggunakan ripping dengan Bulldozer Komatsu D 375 A.

Standar Operasional Prosedur (SOP) dari PT X untuk fragmentasi batubara yang masuk ke dump hopper harus berukuran maksimal $20 \mathrm{~cm}$. Pemberaian batubara yang dilakukan dengan cara ripping menggunakan metode cross ripping (penggaruan silang). Fragmentasi hasil ripping aktual di lokasi penelitian terdapat beberapa ukuran batubara yang lebih dari $20 \mathrm{~cm}$, maka backhoe perlu untuk mengecilkan bongkahan atau memilah ukuran batubara sebelum loading dan akan menghambat waktu loading backhoe.

Hal ini yang melatarbelakangi pentingnya optimalisasi spasi ripping untuk menghasilkan ukuran fragmentasi batubara yang sesuai dan untuk meningkatkan produktivitas backhoe agar menjadi lebih tinggi serta menjaga performa crusher.

\section{Tujuan Penelitian}

1. Mengetahui persentase fragmentasi batubara yang berukuran lebih dari $20 \mathrm{~cm}$ dan berapa produksi bulldozer dan backhoe aktual.

2. Mengetahui persentase fragmentasi batubara yang berukuran lebih dari $20 \mathrm{~cm}$ setelah perbaikan spasi ripping.

3. Mengetahui produksi bulldozer dan backhoe yang dihasilkan setelah perbaikan spasi ripping.

4. Mengetahui upaya apakah yang dilakukan jika target fragmentasi dan target produksi tidak tercapai.

\section{B. Landasan Teori}

\section{Batubara}

Menurut Elliot (dalam Irwandy Arif, 2014), ahli geokimia batubara, berpendapat batubara merupakan batuan sedimen yang secara kimia dan fisika adalah heterogen yang mengandung unsur-unsur karbon, hidrogen, serta oksigen sebagai komponen unsur utama dan belerang serta nitrogen sebagai unsur tambahan.

Menurut Undang-Undang No. 4 Tahun 2009 tentang mineral dan batubara, batubara merupakan endapan senyawa organik karbonan yang terbentuk secara alamiah dari sisa tumbuh-tumbuhan dan bisa terbakar.

Negara Indonesia memiliki standar acuan menurut klasifikasi ASTM. Berikut adalah klasifikasinya :

1. Lignite

2. Sub-bituminus coal

3. Bituminus coal

4. Antracite

Dari lignite sampai dengan anthracite adalah urutan dari batubara rank rendah sampai batubara rank rendah.

\section{Bulldozer}

Menurut Partanto Prodjosumarto (1993), Bulldozer merupakan alat gali dan alat dorong atau alat gusur (dozer) yang kuat serta dapat banyak membantu pekerjaan alat-alat muat.

Metode ripping terdiri atas 2 metode yaitu :

1. Penggaruan Berdampingan atau Parallel Ripping

Cara kerja metode ripping berdampingan dengan melakukan ripping secara sejajar atau berdampingan ke satu arah. Selanjutnya bulldozer akan maju kembali menggaru dengan jarak tertentu.

2. Penggaruan Silang atau Cross Ripping

Metode ini digunakan pada penggaruan material yang relatif keras dan sukar untuk 
diberaikan. Metode yang dilakukan yaitu ripping pada arah vertikal lalu arah horizontal (berlawanan). Tujuannya adalah untuk menghasilkan fragmentasi yang kecil atau sesuai dengan spesifikasi ukuran dump hopper.

\section{Efisiensi Kerja}

Pemanfaatan yang efektif (Effective Utilization) menunjukkan bahwa persen dari seluruh waktu kerja yang tersedia dapat dimanfaatkan untuk kerja produktif. Persamaan dari efisiensi kerja yaitu:

$$
\mathrm{E} . \mathrm{U}=\frac{\mathrm{We}}{\mathrm{We}+\mathrm{R}+\mathrm{S}} \times 100 \%
$$

$$
\begin{array}{ll} 
& \text { Keterangan } \quad: \\
\mathrm{We} & =\text { Waktu efektif (jam) } \\
\mathrm{R} & =\text { Repair hours atau waktu rusak yang berhubungan dengan alat (jam) } \\
\mathrm{S} & \text { = Standby atau waktu bekerja tapi tidak dapat bekerja (jam) }
\end{array}
$$

\section{Faktor Pengembangan atau Swell Factor}

Menurut Partanto Prodjosumarto (1993), swell factor adalah suatu material yang terdapat dialam dalam keadaan padat dan terkonsolidasi dengan baik sehingga sedikit bagian yang kosong atau ruang-ruang yang terisi oleh udara akan tetapi jika material tersebut digali dari tempat aslinya, maka akan terjadi faktor pengembangan atau pemuaian volume (swell) sehingga akan terjadi suatu penambahan volume.

$$
\text { Sweel Factor }=\frac{\rho \mathrm{l}}{\rho \mathrm{i}} \times 100 \%
$$

Keterangan :

$\rho \mathrm{l} \quad=$ Density Loose (ton/LCM)

$\rho \mathrm{i} \quad=$ Density Insitu (ton/BCM)

\section{Faktor Pengisian atau Fill Factor}

Faktor Pengisian atau Fill Factor sangat berpengaruh terhadap kemampuan dari produksi alat -alat mekanis dapat diartikan bahwa faktor pengisian merupakan perbandingan antara volume nyata atau aktual dengan volume teoritis. Maka dari itu, persamaan dari faktor pengisian adalah :

$$
\text { Fill Factor }=\frac{\mathrm{Vn}}{\mathrm{Vt}}
$$

Keterangan :

$\mathrm{Vn} \quad=$ Volume Nyata/Aktual $(\mathrm{LCM})$

$\mathrm{Vt} \quad=$ Volume Teoritis (LCM)

\section{Produktivitas Bulldozer dan Backhoe}

1. Produktivitas Bulldozer

Produktivitas ripping bulldozer menggunakan Giant Shank dengan metode cross ripping atau metode penggaruan silang dengan menggunakan rumus sebagai berikut:

$$
\mathrm{Pb}_{1}=\frac{\left(\frac{3600 \times \mathrm{Eb} \times \mathrm{P} \times \mathrm{S} \times \mathrm{J}}{\mathrm{Cb}}\right)}{2}
$$

Keterangan :

$\mathrm{Pb}_{1}=$ Produktivitas Bulldozer (ton/jam/alat)

$\mathrm{Eb} \quad=$ Efisiensi Kerja Bulldozer (\%) 
$\mathrm{P} \quad=$ Kedalaman Penetrasi Shank $(\mathrm{m})$

$\mathrm{S} \quad=$ Spasi Ripping $(\mathrm{m})$

$\mathrm{J} \quad=$ Jarak ripping $(\mathrm{m})$

$\mathrm{Cb} \quad=$ Cycle Time Bulldozer (detik)

Sedangkan produksi bulldozer $(\mathrm{Pb})$ adalah perkalian Produktivitas $\left(\mathrm{Pb}_{1}\right)$ dengan jumlah bulldozer $\left(\mathrm{n}_{\mathrm{b}}\right)$ :

$\mathrm{Pb}=\mathrm{Pb}_{1} \times \mathrm{n}_{\mathrm{b}}$

2. Produktivitas Bakhoe

Perhitungan produktivitas alat muat dilakukan menggunakan rumus sebagai berikut ini:

$$
\mathrm{Pm}_{1}=\frac{(3600 \times \mathrm{Em}) \times \mathrm{Hm} \times \mathrm{SF} \times \mathrm{FFm}}{\mathrm{CTm}}
$$

Keterangan :

$\mathrm{Pm}=$ Produktivitas alat muat $(\mathrm{BCM} / \mathrm{Jam} / \mathrm{Unit})$

$\mathrm{Em} \quad=$ Efisiensi alat muat $(\%)$

$\mathrm{Hm} \quad=$ Kapasitas bucket $(\mathrm{LCM})$

$\mathrm{SF} \quad=$ Swell Factor $(\%)$

$\mathrm{FF} \quad=$ Fill Factor $(\%)$

$\mathrm{CTm}=$ Cycle time alat muat (detik)

Sedangkan produksi backhoe $(\mathrm{Pm})$ adalah perkalian Produktivitas $\left(\mathrm{Pm}_{1}\right)$ dengan jumlah bulldozer $\left(\mathrm{n}_{\mathrm{m}}\right)$ :

$$
\mathrm{Pm}=\mathrm{Pm}_{1} \times \mathrm{n}_{\mathrm{m}}
$$

\section{Software Split Destop 2.0}

Split desktop adalah software atau program yang berfungsi untuk menganalisa ukuran fragmentasi batuan. Split desktop memiliki beberapa fungsi yaitu :

1. Proses awal, mengkondisikan dan menduplikat hasil foto fragmentasi sehingga foto fragmentasi akan lebih jelas.

2. Menganalisis ukuran fragmentasi berdasarkan range dari ISO, UK, US dan dapat menggunakan range secara manual.

3. Kalkulasi automatic parameter dengan menggunakan pendekatan metode distribusi Rosin Rammler atau Schumann.

\section{Hasil Penelitian dan Pembahasan}

\section{Pengambilan Data}

1. Luas Area Ripping

Luas area ripping dibatasi dengan ukuran $20 \mathrm{~m}$ x $20 \mathrm{~m}$ karena luasan setiap ripping berbeda beda. Rata-rata luas loading point $22,15 \mathrm{~m}$ x 21,10 m sehingga untuk memaksimalkan data cycle time dan pengambilan sampel harus memiliki luasan area yang sama. Sebelum melakukan ripping maka terlebih dahulu adalah membuat patokan luas area $20 \mathrm{~m}$ x $20 \mathrm{~m}$.

2. Pengukuran Shank dan Spasi Ripping

Shank yang digunakan adalah Giant shank dan hasil pengukuran shank pada Bulldozer D 375 A yaitu 1,5 m sedangkan untuk kedalaman atau penetrasi hasil ripping yaitu 1,1 $\mathrm{m}$ dan cara pengukuran spasi ripping yaitu dari shank sampai ke bekas ripping sebelumnya.

3. Pengambilan Sampel

Pengambilan sampel dengan cara mengambil bagian fragmen dari front penambangan yang mengandung ukuran fragmen secara acak. Pola sampling yang digunakan dengan 
blok per $5 \mathrm{~m}$ x $10 \mathrm{~m}$ dari luasan $400 \mathrm{~m}^{2}$ sehingga dihasilkan 8 blok dengan titik sampel yang seragam. Pengambilan foto yaitu dengan skala $3 \times 3 \mathrm{~m}$. Kemudian dipatok $1 \mathrm{~m} \times$ $1 \mathrm{~m}$ untuk menduplikat hasil foto fragmentasi ketika proses input data pada software Split Desktop 2.0.

4. Cycle Time

- Cycle time bulldozer : waktu maju ripping, mundur ripping, belok dan ganti gigi.

- Cycle time backhoe : waktu digging, swing isi, loading dan swing kosong.

Tabel 1. Perbandingan Cycle Time Alat

\begin{tabular}{|l|l|l|l|}
\hline \multirow{2}{*}{ Jenis Alat } & \multicolumn{2}{|l|}{ Cycle Time } \\
\cline { 2 - 4 } & $\begin{array}{l}\text { Spasi Ripping } \\
80 \mathrm{~cm}\end{array}$ & $\begin{array}{l}\text { Spasi Ripping } \\
60 \mathrm{~cm}\end{array}$ & $\begin{array}{l}\text { Spasi Ripping } \\
40 \mathrm{~cm}\end{array}$ \\
\hline $\begin{array}{l}\text { Bulldozer } \\
\text { Komatsu D 375A }\end{array}$ & 48,17 detik & 37,77 detik & 30,3 detik \\
\hline $\begin{array}{l}\text { Backhoe } \\
\text { Hitachi ZX 470Lc }\end{array}$ & 27,3 detik & 26,7 detik & 25,97 detik \\
\hline
\end{tabular}

5. Efisiensi Kerja

Menunjukan kondisi alat yang digunakan dalam pekerjaan dengan memperhatikan kehilangan waktu selama kegiatan produksi berjalan atau selama jam kerja.

Tabel 2. Perbandingan Efisiensi Kerja Alat

\begin{tabular}{|l|l|l|l|}
\hline \multirow{2}{*}{ Jenis Alat } & \multicolumn{3}{|l|}{ Efisiensi Kerja } \\
\cline { 2 - 4 } & $\begin{array}{l}\text { Spasi } \\
\text { Ripping } \\
80 \mathrm{~cm}\end{array}$ & $\begin{array}{l}\text { Spasi Ripping } \\
60 \mathrm{~cm}\end{array}$ & $\begin{array}{l}\text { Spasi Ripping } \\
40 \mathrm{~cm}\end{array}$ \\
\hline $\begin{array}{l}\text { Bulldozer } \\
\text { Komatsu D 375A }\end{array}$ & $84,66 \%$ & $84,66 \%$ & $84,66 \%$ \\
\hline $\begin{array}{l}\text { Backhoe } \\
\text { Hitachi ZX 470Lc }\end{array}$ & $83,29 \%$ & $80,56 \%$ & $72,42 \%$ \\
\hline
\end{tabular}

6. Swell Factor

Swell factor atau faktor pengambangan dilakukan dengan cara pengujian batubara loose dan batubara insitu. Dari hasil pengujian, didapatkan batubara loose yaitu 0,93 ton/LCM dan batubara insitu yaitu 1,26 ton/BCM. Didapatkan hasil perhitungan sebesar $74 \%$.

7. Fill Factor

Fill factor didapatkan dengan perbandingan antara kapasitas bucket aktual dengan kapasitas bucket teoritis. Kapasitas bucket aktual yaitu 2,1 LCM dan kapasitas bucket teoritis yaitu 1,9 LCM. Sehingga hasil fill factor yaitu sebesar 110,53\%. Dari hasil tersebut, maka muatan batubara aktual melebihi kapasitas bucket teoritis.

\section{Pembahasan}

1. Spasi Ripping Aktual $80 \mathrm{~cm}$

- Produksi bulldozer dengan 3 alat yang dihasilkan pada ripping aktual adalah $363.476,74$ ton/bulan.

- Rata-rata persentase fragmentasi batubara yang lebih dari $20 \mathrm{~cm}$ adalah $11,36 \%$. 
- Produksi backhoe dengan 9 alat adalah 363.477,32 ton/bulan.

2. Spasi Ripping Perbaikan $60 \mathrm{~cm}$

- Produksi bulldozer dengan 3 alat yang dihasilkan pada ripping $60 \mathrm{~cm}$ adalah 347.670,27 ton/bulan.

- Rata-rata persentase fragmentasi batubara yang lebih dari $20 \mathrm{~cm}$ adalah 3,05\%.

- Produksi backhoe dengan 9 alat adalah 347.670,7 ton/bulan.

3. Spasi Ripping Perbaikan $40 \mathrm{~cm}$

- Produksi bulldozer dengan 3 alat yang dihasilkan pada ripping $40 \mathrm{~cm}$ adalah 288.922,03 ton/bulan.

- Rata-rata persentase fragmentasi batubara yang lebih dari $20 \mathrm{~cm}$ adalah $1,58 \%$.

- Produksi backhoe dengan 9 alat adalah 288.922,90 ton/bulan.

Tabel 3. Perbandingan Produksi Alat

\begin{tabular}{|l|l|l|l|}
\hline \multirow{2}{*}{ Jenis Alat } & \multicolumn{3}{|l|}{ Produksi Alat } \\
\cline { 2 - 4 } & $\begin{array}{l}\text { Spasi Ripping } \\
80 \mathrm{~cm}\end{array}$ & $\begin{array}{l}\text { Spasi Ripping } \\
60 \mathrm{~cm}\end{array}$ & $\begin{array}{l}\text { Spasi Ripping } \\
40 \mathrm{~cm}\end{array}$ \\
\hline $\begin{array}{l}\text { Bulldozer } \\
\text { Komatsu D 375A }\end{array}$ & $\begin{array}{l}363.476,74 \\
\text { ton/bulan }\end{array}$ & $\begin{array}{l}347.670,27 \\
\text { ton/bulan }\end{array}$ & $\begin{array}{l}288.922,03 \\
\text { ton/bulan }\end{array}$ \\
\hline $\begin{array}{l}\text { Backhoe } \\
\text { Hitachi ZX 470Lc }\end{array}$ & $\begin{array}{l}363.477,32 \\
\text { ton/bulan }\end{array}$ & $\begin{array}{l}347.670,7 \\
\text { ton/bulan }\end{array}$ & $\begin{array}{l}288.922,9 \\
\text { ton/bulan }\end{array}$ \\
\hline
\end{tabular}

4. Usaha Perbaikan Produksi

Target produksi Pit 1 Timur, Banko Barat adalah 360.000 ton/bulan dan untuk batas fragmentasi yang lebih dari $20 \mathrm{~cm}$ adalah $2 \%$. Dari hasil perhitungan, didapatkan hasil fragmentasi yang optimal adalah dengan spasi ripping $40 \mathrm{~cm}$ dengan persentase fragmentasi sebesar $1,58 \%$. Spasi ripping $40 \mathrm{~cm}$ akan menghasilkan waktu ripping bulldozer yang lama sehingga meningkatkan waktu hambatan backhoe untuk tunggu ripping. Maka perbaikan yang dilakukan adalah dengan penambahan 1 alat bulldozer. Dengan dilakukannya penambahan alat maka diperoleh hasil produksi yaitu 385.229,37 ton/bulan. Sedangkan untuk backhoe dengan peningkatan efisiensi kerja didapatkan produksi 388.229,60 ton/bulan.

\section{Kesimpulan}

1. Persentase fragmentasi batubara B2 untuk ripping aktual dengan spasi $80 \mathrm{~cm}$ menghasilkan ukuran fragmentasi batubara lebih dari $20 \mathrm{~cm}$ adalah $11,36 \%$ dengan ukuran maksimal $36,27 \mathrm{~cm}$. Sedangkan produksi ripping bulldozer sebesar $363.476,74$ ton/bulan dan produksi penggalian dan pemuatan backhoe sebesar 363.477,32 ton/bulan.

2. Persentase fragmentasi batubara $\mathrm{B} 2$ pada perbaikan spasi ripping $60 \mathrm{~cm}$ menghasilkan ukuran fragmentasi batubara lebih dari $20 \mathrm{~cm}$ adalah 3,05\% dengan ukuran maksimal sebesar $25,73 \mathrm{~cm}$. Sedangkan untuk perbaikan spasi ripping $40 \mathrm{~cm}$ menghasilkan ukuran fragmentasi batubara lebih dari $20 \mathrm{~cm}$ adalah 1,58\% dengan ukuran maksimal sebesar 21,4 cm.

3. Produksi ripping bulldozer dengan spasi $60 \mathrm{~cm}$ adalah $347.670,27$ ton/bulan sedangkan untuk spasi $40 \mathrm{~cm}$ adalah 288.922,03 ton/bulan. Untuk produksi backhoe dengan ripping $60 \mathrm{~cm}$ yaitu $347.670,7$ ton/bulan sedangkan untuk ripping $40 \mathrm{~cm}$ adalah $288.922,9$ ton/bulan.

4. Untuk mencapai target produksi 360.000 ton/bulan dengan persentase fragmentasi batubara yang lebih dari $20 \mathrm{~cm}$ berjumlah maksimal $2 \%$, maka diperlukan penambahan satu alat bulldozer dan menaikan efisiensi kerja backhoe. Dari hasil perhitungan 
sesudah penambahan satu alat bulldozer dengan asumsi spasi ripping $40 \mathrm{~cm}$ didapatkan produksi sebesar 385.229,37 ton/bulan dan menaikan efisiensi kerja pada backhoe didapatkan produksi sebesar 385.229,60 ton/bulan.

\section{E. Saran}

1. Rekomendasi spasi ripping yaitu $40 \mathrm{~cm}$, hal tersebut merupakan SOP dari pengoperasian bulldozer menurut pengawas penambangan Pit 1 Timur (wawancara) sehingga akan menghasilkan fragmentasi batubara yang lebih kecil dari $20 \mathrm{~cm}$.

2. Dibutuhkan pengawasan yang lebih untuk operator bulldozer karena akan mempengaruhi kinerja dari operator bulldozer sehingga ripping yang dihasilkan akan sesuai dengan ketentuan dump hopper 3 yaitu kurang dari $20 \mathrm{~cm}$.

3. Dilakukan penambahan satu alat bulldozer karena dapat meningkatkan hasil produksi bulldozer dan dapat meningkatkan efisiensi dari backhoe.

\section{Daftar Pustaka}

[1] Anonim, 1998, Classification of Coal Rank, Amerika Serikat : American Society for Testing and Materials International.

[2] Arif, I., 2014, Batubara Indonesia, Jakarta : PT Gramedia Pustaka Utama

[3] Dahlan, M.B., 2015, Geologi Untuk Pertambangan Umum, Yogyakarta : Graha Ilmu

[4] Gerry.,dkk, 2016, Analisis Kemampugaruan Massa Batuan Berdasarkan Metode Rock Mass Rating Pit S22GSB1 PT Kitadin Embalut Site Tenggarong Seberang Kutai Kartanegara Kalimantan Timur, Jurnal Teknologi Mineral FT UNMUL, 4(1), 31-38.

[5] Indonesianto, Y., 2005, Pemindahan Tanah Mekanis, Yogyakarta : Teknik Pertambangan UPN "Veteran" Yogyakarta

[6] Muchjidin, 2013, "Pemanfaatan Batubara”, Bandung : Institut Teknologi Bandung.

[7] Pemerintah Republik Indonesia, 2009, "Undang-Undang Republik Indonesia Nomor 4 Tahun 2009 Tentang Pertambangan Mineral dan Batubara, Jakarta : Sekretariat Negara.

[8] Prodjosumarto, P., 1993, Pemindahan Tanah Mekanis, Bandung : Institut Teknologi Bandung

[9] Susanti, Zaenal dan Pramusanto, 2017, Kajian Teknis Produktivitas Gali-Muat dan Alat Angkut pada Kegiatan Pengupasan Overburden Pit 4200 Blok 1E - South Block 1 PT Trubaindo Coal Mining, Kecamatan Muara Lawa, Kabupaten Kutai Barat, Provinsi Kalimantan Timur, Jurnal Spesia Prosiding Teknik Pertambangan Unisba, 3(1), 96-103. 